\title{
Mesenchymal Stem Cells Therapy Improved the Streptozotocin-Induced Behavioral and Hippocampal Impairment in Rats
}

\author{
María F. Zappa Villar ${ }^{1}$ • Juliette López Hanotte ${ }^{1}$. Joaquín Pardo ${ }^{1}$. Gustavo R. Morel ${ }^{1}$. Guillermo Mazzolini ${ }^{2}$. \\ Mariana G. García ${ }^{2}$ Paula C. Reggiani ${ }^{1,3}$ (1)
}

Received: 2 April 2019 / Accepted: 31 July 2019 /Published online: 10 August 2019

(C) Springer Science+Business Media, LLC, part of Springer Nature 2019

\begin{abstract}
Sporadic Alzheimer's disease (sAD) is the most prevalent neurodegenerative pathology with no effective therapy until date. This disease promotes hippocampal degeneration, which in turn affects multiple cognitive domains and daily life activities. In this study, we hypothesized that long-lasting therapy with mesenchymal stem cells (MSC) would have a restorative effect on the behavioral alterations and cognitive decline typical of SAD, as they have shown neurogenic and immunomodulatory activities. To test this, we chronically injected intravenous human MSC in a SAD rat model induced by the intracerebroventricular injection of streptozotocin (STZ). During the last 2 weeks, we performed open field, Barnes maze, and marble burying tests. STZ-treated rats displayed a poor performance in all behavioral tests. Cell therapy increased exploratory behavior, decreased anxiety, and improved spatial memory and marble burying behavior, the latter being representative of daily life activities. On the hippocampus, we found that STZ promotes neuronal loss in the Cornus Ammoni (CA1) field and decreased neurogenesis in the dentate gyrus. Also, STZ induced a reduction in hippocampal volume and presynaptic protein levels and an exacerbated microgliosis, relevant $\mathrm{AD}$ features. The therapy rescued $\mathrm{CA} 1$ neurodegeneration but did not reverse the decrease of immature neurons, suggesting that the therapy effect varied among hippocampal neuronal populations. Importantly, cell therapy ameliorated microgliosis and restored hippocampal atrophy and some presynaptic protein levels in the sAD model. These findings, by showing that intravenous injection of human MSC restores behavioral and hippocampal alterations in experimental sAD, support the potential use of MSC therapy for the treatment of neurodegenerative diseases.
\end{abstract}

Keywords Sporadic Alzheimer's disease $\cdot$ Mesenchymal stem cell $\cdot$ Cognitive function $\cdot$ Microglia $\cdot$ Synaptic proteins

Electronic supplementary material The online version of this article (https://doi.org/10.1007/s12035-019-01729-z) contains supplementary material, which is available to authorized users.

María F. Zappa Villar

mfzappa@med.unlp.edu.ar

Paula C. Reggiani

paulareggiani@conicet.gov.ar

1 Institute for Biochemical Research (INIBIOLP) - National Scientific and Technical Research Council (CONICET) - School of Medical Sciences, National University of La Plata (UNLP), CC 455, Zip 1900, La Plata, Argentina

2 Gene Therapy Laboratory, IIMT, Facultad de Ciencias Biomédicas, CONICET-Universidad Austral, Buenos Aires, Argentina

3 Department of Cytology, Histology and Embryology B, School of Medical Sciences, UNLP, La Plata, Argentina

\section{Introduction}

Alzheimer's disease (AD) is the most common cause of dementia, accounting for an estimated 60 to $80 \%$ of cases [1]. It is characterized by a progressive loss of memory and cognitive functions. The predominant cases are sporadic Alzheimer's disease (sAD), which is multifactorial and involves several etiopathogenic mechanisms. Neuroinflammation, head trauma, impaired brain glucose/energy metabolism, and diabetes are some of the risk factors for SAD [2]. Anatomical signs of AD include progressive brain atrophy, particularly in the hippocampus. Specifically, the Stratum Radiatum (SR) and the pyramidal layer of Cornus Ammonis 1 (CA1) are hippocampal regions highly susceptible to AD [3-5]. However, other hippocampal areas may present alterations, such as the dentate gyrus (DG), where the granular cells show morphological changes [6]. Importantly, these degenerative modifications 
correlate with cognitive decline in $\mathrm{AD}$, supporting their potential as early biomarkers [3].

Novel and effective therapeutic approaches for SAD are urgently needed, which should be tested pre-clinically in animal models of the disease. A rodent model that mimics many aspects of SAD-type neurodegeneration has been generated by an intracerebroventricular (icv) injection of streptozotocin (STZ) [7-10]. Several studies have provided evidence that a single icv-STZ injection in middle-aged rats reduces the central metabolism of glucose and concomitantly impairs cognitive function and extensive neuroinflammation involving activation of both astrocytes and microglia [11-16].

There is an increasing interest in the therapeutic potential of mesenchymal stem cells (MSC) in the brain, as they are able to modulate inflammatory responses [17-19] and migrate to injury sites [20-22]. In particular, birth-associated tissues represent a very promising source and are under study as advantageous candidates for cell therapy due to their lower donor variability, faster doubling time, and ready availability, avoiding the need of invasive procedures and eliminating other ethical concerns [23-27].

Even though there have been some works on the effect of MSC therapy to treat neurodegenerative diseases [28-32], in vivo studies for $\mathrm{SAD}$ are still limited. The goal of the current study was to evaluate the neuroprotective potential of human umbilical cord MSC against the deleterious effects caused by the rat brain exposure to STZ as a SAD model. To this end, we assessed the effects of chronic intravenous (iv) injection of MSC on cognition and behavior in this model. In addition, since the hippocampus is particularly affected in $\mathrm{AD}$, we focused our analysis on this brain region. Specifically, we studied SR volume, mature and immature neurons, glial cells, and synaptic markers to support the potential of systemic MSC therapy for the treatment of sAD.

\section{Material and Methods}

\section{Animals}

For this work, 3-month-old male Sprague-Dawley (SD) rats weighing 280-330 g (INIBIOLP, School of Medical Sciences, University of La Plata, La Plata city, Argentina) were used. Three animals were housed per cage in a temperaturecontrolled room $\left(22-24{ }^{\circ} \mathrm{C}\right)$ on a 12 -h light/12-h dark cycle (lights on $7 \mathrm{am}-7 \mathrm{pm}$ ) with food and water available ad libitum.

\section{Isolation of MSC}

MSC were isolated from human umbilical cord perivascular tissue obtained from healthy donors at the Hospital Universitario Austral (Pilar, Buenos Aires, Argentina) as previously described [24]. MSC were characterized according to the International Society for Cellular Therapy guidelines [33], as previously described [20].

\section{Experimental Design}

On experimental day 0 , animals were anesthetized with ketamine hydrochloride ( $40 \mathrm{mg} / \mathrm{kg}$; ip) plus xylazine ( $8 \mathrm{mg} / \mathrm{kg}$; im) and placed in a stereotaxic apparatus. Rats were randomly divided into three experimental groups, 7 animals each: (A) SHAM, each rat received a bilateral icv injection $(5 \mu \mathrm{l} /$ ventricle) of artificial cerebrospinal fluid (aCSF) $(120 \mathrm{mM} \mathrm{NaCl}$, $3 \mathrm{mM} \mathrm{KCl}, 1.15 \mathrm{mM} \mathrm{CaCl}_{2}, 0.8 \mathrm{mM} \mathrm{MgCl} 2,27 \mathrm{mM}$ $\mathrm{NaHCO}_{3}$, and $0.33 \mathrm{mM} \mathrm{NaH}_{2} \mathrm{PO}_{4}, \mathrm{pH}$ 7.4). (B) STZ and (C) STZ + MSC (Fig. 1a). Each rat of groups $B$ and $C$ received a bilateral icv injection of STZ (Sigma-Aldrich, CAS\#18883-664) at a dose of $3 \mathrm{mg} / \mathrm{kg}$. A STZ volume of $5 \mu \mathrm{l} / \mathrm{ventricle} \mathrm{was}$ administered. The stereotaxic coordinates for icv infusion were measured as $0.92 \mathrm{~mm}$ posterior to bregma, $1.5 \mathrm{~mm}$ lateral to sagittal suture, and $3.9 \mathrm{~mm}$ beneath the brain surface [34]. Following surgery, a single dose of ampicillin was injected.

For the MSC therapy, animals were injected in a tail vein; each rat of $\mathrm{C}$ group received an iv-saline suspension of $1 \mathrm{ml}$ containing $1 \times 10^{6} \mathrm{MSC}$ on days $24,42,60$, and 78 (every 18 days). Cell therapy started on day 24 based on our previous studies showing that at this stage, the STZ rats already display cognitive deficits.

For the open field (OF) test protocol, rats were individually placed into the center of the open arena on day 86 and allowed to explore the apparatus for $5 \mathrm{~min}$. After the 5-min test, rats were returned to their home cages. Two days later, rats were submitted to the Barnes maze (BM) protocol for 4 days, which consisted on the habituation plus 3 days with 2 acquisition trials (ATs) each. On day 92, $24 \mathrm{~h}$ after the last AT (AT6), rats were submitted to the probe trial (PT). On the following day, the Marble burying (MB) test was performed. All rats were euthanized on day 95 by rapid decapitation.

\section{Exploratory and Anxiety Behavior}

The OF test [35] consisted of a square box $(65 \times 65 \times 45 \mathrm{~cm})$, whose floor was divided into 16 equal squares. Rats were placed in the center of the arena and allowed to explore freely for $5 \mathrm{~min}$. The behavioral variables were the following:

Crossing: number of grid lines crossed by the rat with all four paws. A high frequency of this behavior indicates increased locomotion and exploration and/or a lower level of anxiety.

Center square entries: frequency of entry to the inner area by the rat with all four paws into the central square. A high frequency/duration of this behavior indicates high exploration and low anxiety [36, 37]. 
Grooming: time a rat spent scratching or licking itself. This behavior has proved to be useful in the behavioral investigation of anxiety and stress [38].

\section{Spatial Memory Assessment}

The modified BM protocol used here was previously documented $[15,39]$. In brief, it consists of an elevated black acrylic circular platform, $122 \mathrm{~cm}$ in diameter, containing 20 holes around the periphery. The escape hole is numbered as hole 0 for graphical normalized representation purposes, while the remaining holes are numbered 1 to 10 clockwise, and -1 to -9 counterclockwise. A 90-dB white-noise generator and a white-light $500-\mathrm{W}$ bulb provided the escape stimuli from the platform. At the beginning of the experiment, rats were habituated to the task. An AT consists of placing a rat in the starting chamber, located at the center of the platform for $30 \mathrm{~s}$; the chamber is then raised, the aversive stimuli (bright light and high pitch noise) are switched on, and the rat is allowed to freely explore the maze for $120 \mathrm{~s}$. The purpose of ATs is to train the rats to find the escape box (hole 0 ). The PT is similar to an AT except that the escape box is removed; its purpose is to assess recent spatial memory retention in $120 \mathrm{~s}$. Behavioral parameters assessed were as follows:

Spatial learning parameters:

Latency. Time a rat spent since its release from the start chamber until it enters the escape box (during an AT), or until the first exploration of the escape hole (during the PT).

Errors. Number of explorations of holes different from the escape one. Each exploration of an incorrect hole is counted as an error, provided that the rat lowers its nose below the plane of the table surface.

Spatial memory parameters:

Hole exploration frequency. The explorations number for each hole of the maze, during the PT.

Exploration frequency in goal sector (GS). The sum of explorations number for the hole 0 divided by the sum of total explorations number, during the PT.

The seeking behavior for the escape hole was used to categorize rats' search strategies per trial based as follows [40]:

Direct-to-goal. Scored when all exploration-involved holes were within two holes from the goal and fewer than 3 total errors were made.

Serial search. Scored when at least 3 errors were made and $75 \%$ of holes explored were adjacent or within 1 hole of each other and when animals searched them in order.
Random search. Scored when at least 3 errors were made and when $50 \%$ of holes explored were non-adjacent or non-localized to a given maze quadrant (4-hole span) or when animals made more than 2 changes of direction or traverses across the maze center.

\section{Marble Burying Behavior}

MB test is based on the observation that rodents bury either harmful or harmless objects (e.g., glass marbles) in their bedding [41]. Marble burying is considered as a species-typical behavior and has been related to hoarding in rats [41]. This test was carried out 94 days after icv-STZ injection. Individual subjects were placed in a housing cage $(30 \times 30 \times 17 \mathrm{~cm})$ with $5 \mathrm{~cm}$ of fresh hardwood chip bedding. An array of 16 glass marbles $(1.5 \mathrm{~cm}$ in diameter, arranged in a $4 \times 4$ grid $)$ was evenly spaced over the surface. The number of marbles buried during a 30 -min period was analyzed. In this procedure, a marble was considered buried if at least $2 / 3$ of the marble were covered with bedding [42].

\section{Brain Processing and Immunohistochemistry}

Brains were rapidly removed and divided into right and left hemispheres. The left hemispheres were fixed in phosphatebuffered para-formaldehyde $4 \%(\mathrm{pH} 7.4)$ overnight at $4{ }^{\circ} \mathrm{C}$. Afterwards, brains were reserved in cryoprotectant solution (30\% ethylene glycol, $1 \%$ polyvinylpyrrolidone, $30 \%$ sucrose, in phosphate buffer $0.1 \mathrm{M}, \mathrm{pH} 7.4$ ) at $-20{ }^{\circ} \mathrm{C}$ until use for immunohistochemistry. For this aim, brains were cut coronally in $40-\mu \mathrm{m}$-thick sections with a vibratome (VT1000S; Leica Microsystems). From the right brain hemispheres, the hippocampus was carefully dissected as previously described [43] and stored at $-80{ }^{\circ} \mathrm{C}$ until Western blot (WB) analysis.

\section{Immunohistochemistry}

All immunohistochemistry techniques were performed on free-floating sections. For each animal, separate sets of sections were processed using the following antibodies: goat antiDoublecortin (DCX) polyclonal antibody (immature neurons marker; 1:250; Santa Cruz Biotech c-18, Dallas, TX); mouse anti-NeuN antibody (neuronal marker; 1:850; Millipore Cat\#MAB377); rabbit anti-Iba1 polyclonal antibody (microglial cells marker, 1:1000; Wako Cat\#016-20001); and rabbit anti-Glial fibrillary acidic protein (GFAP) polyclonal antibody (astrocyte marker; 1:1500; DAKO Cat\#Z0334). Briefly, after overnight incubation at $4{ }^{\circ} \mathrm{C}$ with the primary antibody, sections were incubated with biotinylated horse antigoat antibody (1:300; Vector Laboratories Cat\#BA-9500), goat anti-mouse antibody (1:300; Vector Laboratories 


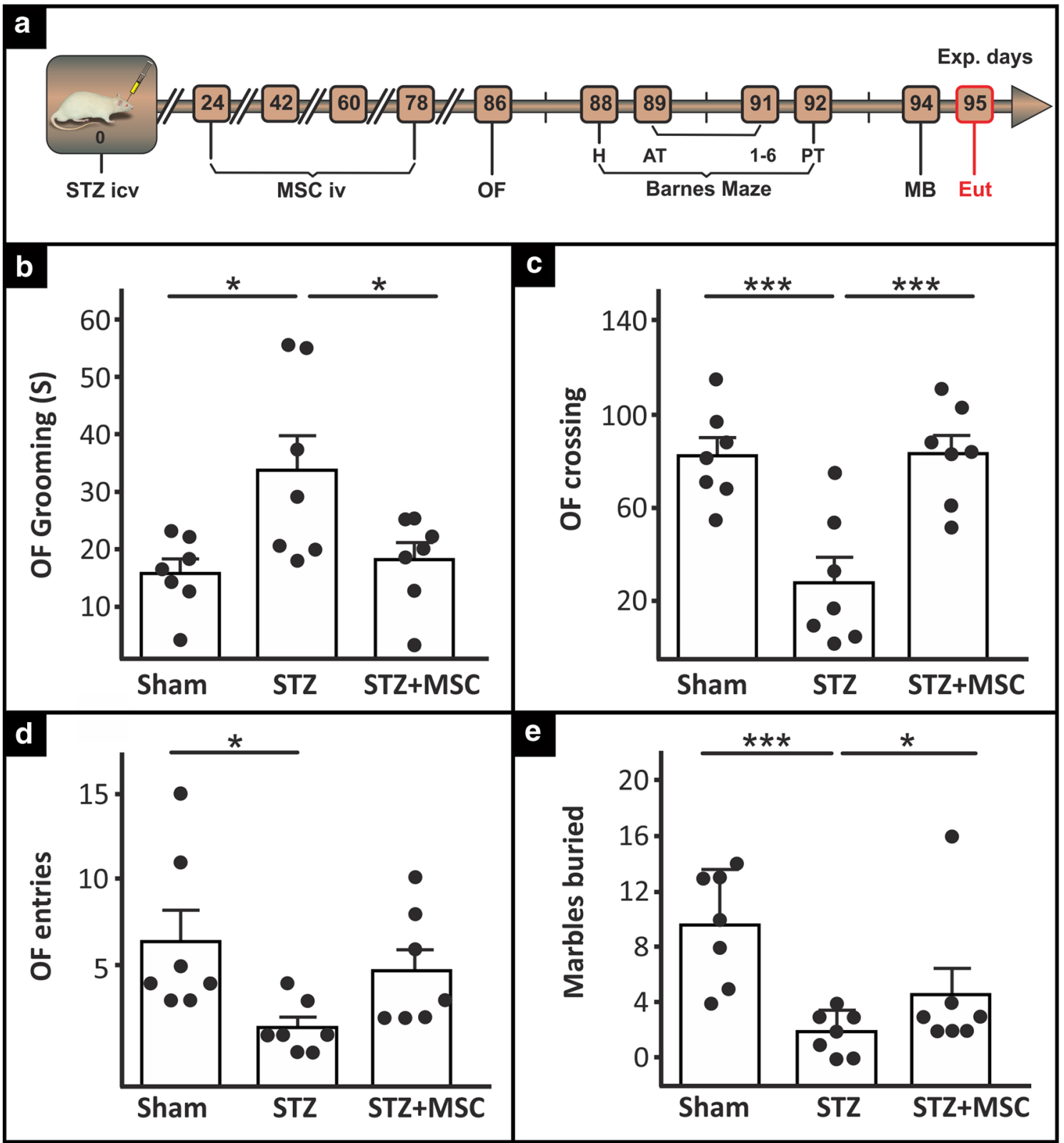

Fig. 1 Experimental design and MSC therapy effect on behavioral performance in open field test and marble burying test. On ED 0, STZ ( $3 \mathrm{mg} / \mathrm{kg}$ ) or aCSF was stereotaxically injected (icv). On days $24,42,60$, and $78, \mathrm{STZ}+\mathrm{MSC}$ group received $1 \times 10^{6} \mathrm{MSC}$ iv. On ED + 86, OF test was performed. Barnes maze habituation was performed on $\mathrm{ED}+88$; subsequently, on $\mathrm{ED}+89$ onward $\mathrm{ED}+91$, all animals were submitted to $120 \mathrm{~s}$ AT $(2 \times$ day). PT was performed on $\mathrm{ED}+92$. On $\mathrm{ED}+94, \mathrm{MB}$ test was performed. Finally, on ED +25 rats were sacrificed and their brains were removed for further analysis (a). During the OF, there was a significant increase in grooming (b), together with a reduction of crossing (c), and entries to the inner area (d) in the STZ-treated rats. MSC treatment restored the grooming and crossing to normal values, but not the entries. In the MB test, it is observed that cell therapy causes a significant increase in the number of buried balls (e), a parameter previously affected by STZ. Abbreviation: $a C S F$, artificial cerebrospinal fluid; $A T$, acquisition trial; $E D$, experimental day; $H$, habituation; $i c v$, intracerebroventricular; $i v$, intravenously; $M B$, marble burying test; $O F$, open field test; $P T$, probe trial. $N=7$ per group. All data were represented as mean \pm SEM. Comparisons were made between groups. $* P<0.05 ; * * P<0.01$; $* * * P<0.001$. The undepicted comparisons account for a non-significant difference between groups

chloride (DAB) (Vector Laboratories Cat\#SK-4600). DAB revealed sections were counterstained with cresyl violet (Nissl staining) as described elsewhere [39].

Finally, sections were dehydrated and mounted with Vectamount (Vector Laboratories) and used for image analysis. then incubated with 3,3-diamino benzidinetretrahydro- 


\section{Image Analysis}

As mentioned earlier, we focused our stereological assessment on $\mathrm{NeuN}(+)$ mature neurons of the CA1, DCX $(+)$ immature neurons in the DG, and $\mathrm{Iba} 1(+)$ microglial cells and GFAP $(+)$ astrocytes cells in the SR. The SR upper limit is the CA1 pyramidal layer, lower limit is Stratum Lacunosum Moleculare, and lateral limit is the Stratum Lucidum of the dorsal hippocampus [34]. The total number of cells was estimated using a modified version of the optical dissector method [6]. Individual estimates of the total cell number (n) were calculated according to the following formula: $n=\mathrm{RQR} .1 /$ ssf.1/asf.1/tsf, where RQR is the sum of counted cells, ssf is the section sampling fraction, asf is the area sampling fraction, and tsf is the thickness sampling fraction, as previously described [39, 44]. All morphological parameters were assessed unilaterally in the left hippocampus. The microscopical analysis was performed with an Olympus BX-51 microscope attached to an Olympus DP70 CCD video camera (Tokyo, Japan). In each hippocampal block, one out of six serial sections was selected in order to obtain a set of non-contiguous serial sections spanning the dorsal hippocampus.

\section{Volume of the Stratum Radiatum}

In order to assess the volume of the SR, a stereological approach on rat brain coronal sections was carried out. Four NeuN immunoreactive (NeuNir) sections were sampled, with a separation of $240 \mu \mathrm{m}$ along the anterior-posterior axis. Our region of interest was set up as the area delimited by the CA1 pyramidal layer as the upper limit, the Stratum Lacunosum Moleculare as lower limit and a width of $520 \mu \mathrm{m}$ as lateral limit, whose midpoint was the peak point of curvature in the pyramidal layer.

\section{Immature Neurons Analysis}

Doublecortin immunoreactive (DCXir) cell number was assessed in the DG, which includes the hippocampal subgranular zone and granular cell layer [34], as previously described in the "Volume of the Stratum Radiatum" section, with asf $=1$, tssf $=1 / 6$, and tsf $=1$. Four DCX-stained sections per animal were sampled. Estimates were based on counting DCXir cell bodies as they came into focus.

\section{Mature Neurons Analysis}

Mature neurons were detected as NeuNir cells. We determined NeuN immunoreactive area (IRA) and considered a decrease within as an overt sign of SAD-mediated neurodegeneration. For this purpose, 5 sections per animal and 3 fields per section corresponding to NeuNir neurons in the CA1 pyramidal layer were digitally segmented using the Image Pro Plus v5.1 software (IPP, Media Cybernetics). For each calculation, background was determined by manually adjusting the system density window as previously described [45], until only the NeuNir neurons were selected. For each animal, the sum of immunoreactive areas was multiplied by the section sampling number (NeuNir area $\times 6$ ).

\section{Microglial Cell Analysis}

Microglial cells were identified as Ibal immunoreactive (Iba1ir) cells in the hippocampal SR. The Ibalir cell number was estimated as previously described in the "Volume of the Stratum Radiatum" section, with asf $=0.387, \mathrm{ssf}=1 / 6$, and $\mathrm{tsf}=1$. Five sections per animal and three corresponding SR fields per section were analyzed. Ibalir cells were morphologically classified as types I, II, III, IV, and V based on previously documented criteria $[15,46]$. Types I, II, and III were categorized as non-reactive glia, whereas types IV and V were considered reactive. The Ibalir reactive and non-reactive cell percentage of each animal group was calculated.

\section{Astroglial Cell Analysis}

Morphological assessment of GFAP immunoreactive (GFAPir) astrocytes was performed in the SR. To estimate the GFAP IRA occupied by cell bodies and processes, GFAPir astrocytes were segmented as described in the "Microglial Cell Analysis" section; for each animal, the sum of immunoreactive areas was multiplied by the section sampling number (GFAPir area $\times 6$ ). The total number of cells was estimated as previously described in the "Volume of the Stratum Radiatum" section, with asf $=1, \mathrm{ssf}=1 / 6$, and tsf $=$ 1. Five sections per animal and three corresponding SR fields per section were analyzed. Additionally, to study branching complexity, GFAPir astrocytes were submitted to the Sholl analysis [47]. The length of the astrocyte processes and their branching complexity at every distance from the soma were averaged, and these output data were used for the statistical analysis between groups as we have previously described [15].

\section{Western Blot Analysis}

\section{Sample Preparation}

In order to obtain protein lysates, right hemi-hippocampi were homogenized with precooled RIPA buffer $(150 \mathrm{mM}$ $\mathrm{NaCl}, 1 \%$ Triton $\mathrm{X}-100,0.5 \%$ sodium deoxycolate, $0.1 \%$ sodium dodecyl sulfate (SDS), $50 \mathrm{mM}$ Tris- $\mathrm{HCl} \mathrm{pH} 8$, and appropriate protease inhibitors, $\mathrm{pH}$ 7.4). Finally, protein concentration was measured by Bradford protein assay. Bovine serum albumin (BSA, 0.1-1 mg/ml) was 
used as a standard. Samples were aliquoted and stored at $-80{ }^{\circ} \mathrm{C}$.

\section{Immunoblotting}

Equal amounts of protein $(50 \mu \mathrm{g})$ for every sample were separated by $10 \%$ SDS-PAGE and transferred to nitrocellulose membranes (Bio-Rad). The membranes were blocked by incubation in 5\% non-fat milk in Tris-buffered saline/Tween-20 (TBS-T) for $1 \mathrm{~h}$ at room temperature and then incubated with primary antibodies against synaptotagmin 1 (SYT1) (1:200; mAb 48 (asv 48), DSHB), synaptotagmin 2 (SYT2) (1:150; Znp-1, DSHB), synaptophysin (SYP) (1:200; Santa Cruz Biotechnology, sc-17750), synaptic vesicle protein 2 (SV2) (1:200; SV2, DSHB), glutamic acid decarboxylases (GAD) (1:200; Santa Cruz Biotechnology, sc-365180), in their isoforms GAD65 and 67, vinculin (1:200; Santa Cruz Biotechnology, sc-73614), and $\beta$-actin (1:1000; Santa Cruz Biotechnology, sc-47778), overnight at $4{ }^{\circ} \mathrm{C}$. Then, membranes were washed with TBS-T and incubated with the secondary antibody conjugated with horseradish peroxidase (1:20000, Jackson ImmunoResearch Laboratories, Inc., \#115-035-003) for $3 \mathrm{~h}$ at room temperature. After being washed with TBS-T, membrane visualization was performed with Super Signal West Pico PLUS Chemiluminescent substrate (Thermo Fisher Scientific, \#34577) on a Chemidoc Image Station (Bio-Rad, Hercules, CA, USA). Relative optical density of protein bands was analyzed using a gel documentation system. Sample loading for SYP and SYT1 was normalized to relative density of the Vinculin band. Sample loading for SYT2, SV2, GAD65, and GAD67 was normalized to relative density of the $\beta$-actin band.

\section{Statistical Analysis}

For BM latency, errors and search strategies analysis data from each AT were averaged; these parameters together with Ibalir reactive and non-reactive cells were analyzed by twoway analysis of variance (ANOVA) with repeated measures. The remaining behavioral and stereological data were analyzed by one-way ANOVA. Tukey's multiple comparison post-hoc tests were used where appropriate. All analyses were conducted by statistical software, GraphPad Prism 6 (GraphPad Software, San Diego, CA, USA).

\section{Results}

\section{MSC Therapy Improved Exploratory, Anxiety, and Species-Typical Burying Behavior}

The OF test is a widely used procedure for examining the behavioral effects of treatments and anxiety. In the OF test,
STZ injection induced an increase in grooming behavior, which was reversed by the stem cell treatment (one-way ANOVA $\left.F_{(2,18)}=5.379 ; P=0.0147\right)($ Fig. $1 b)$ and a decrease in the number of quadrant crossings, also restored by the therapy (one-way ANOVA $F_{(2,18)}=13.05, P=0.0003$ ) (Fig. 1c). The STZ treatment led to a decrease in the number of entries to the inner area; the STZ + MSC group displayed a higher number of entries than STZ group, but this difference was not significant (one-way ANOVA $F_{(2,18)}=3.858, P=0.0403$ ) (Fig. 1d). In the marble burying test, the STZ group buried fewer marbles; this species-typical burying behavior was improved by the MSC therapy (one-way ANOVA $F_{(2,18)}=$ $12.72, P=0.0004$ ) (Fig. 1e).

\section{MSC Therapy Improved Spatial Learning and Memory}

In order to evaluate hippocampal-dependent spatial behavior, we performed the BM test. The groups displayed no statistically significant difference in learning performance, as depicted by the ATs learning curves for both errors and latencies (two-way ANOVA group factor $F_{(2,18)}=0.3304, P=$ $0.7229 ; F_{(2,18)}=0.7565, P=0.4837$, respectively) (Fig. 2a, b). Regarding memory evaluated in the PT, the STZ group made more errors than the SHAM control; interestingly, upon MSC therapy, the subjects made significantly fewer errors (one-way ANOVA $F_{(2,18)}=4.944, P=0.0194$ ) (Fig. 2c). The same tendency was observed for the PT latency, though no significant differences were found for this parameter (one-way ANOVA $F_{(2,18)}=2.952, P=0.0779$ ) (Fig. 2d). We also analyzed the escape strategies of the animals in the second trial of each experimental day. STZ group inclined towards a random strategy to escape the maze (Fig. 2e, f); the therapy promoted a shift of some STZ subjects towards a serial strategy (two-way ANOVA group factor $F_{(2,18)}=4.167$, $P=0.0326$ ). In order to get a clear rendering of the number of hole explorations of each animal during the PT, we constructed sunflower plots, from where we observed that the STZ subjects explored all holes at random to a greater extent. This behavior was restored by the MSC therapy, since the exploration was shifted to the goal sector (Fig. 2g). The STZ treatment caused a decrease in the percentage of exploration frequency in the GS; the STZ + MSC group displayed a higher number of this parameter as compared with STZ group, but this difference was not significant (one-way ANOVA $F_{(2,18)}=$ 4.413, $P=0.0276$ ) (Fig. 2h).

\section{MSC Therapy Restored Hippocampal Volume and CA1 Neuron Count but Did Not Reverse Neurogenesis Fall}

The SAD pathological process involves neuronal changes in the histological structure and volume of the hippocampus. Thus, we examined the hippocampal neuronal populations and the SR volume. STZ injection induced a frank decrease 


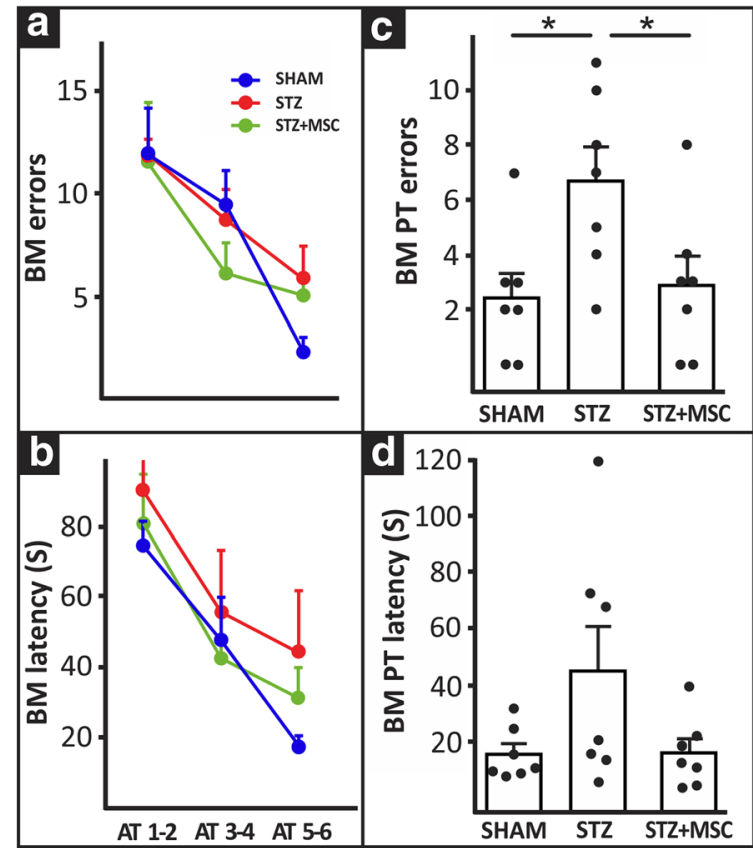

Fig. 2 MSC therapy effect on behavioral performance in the Barnes Maze test. Errors and latency to the escape box in BM ATs (a and b, respectively) and PT (c and d, respectively). There is an increase in the number of errors made during PT by the STZ animals and a decrease in the STZ + MSC group (c), but no differences were observed in learning errors (a). Regarding latency (b and d), no significant differences were observed between the groups. Schematic representation of the maze from above, containing 20 holes around the periphery and the search strategies: direct, serial, and random (e). STZ group showed a significant use of random search strategy, i.e., increase in strategies score (f), while SHAM rats exhibit a preference for direct strategy; the therapy

in the SR volume, which was reversed by the stem cell therapy (one-way ANOVA $F_{(2,18)}=6.021, P=0.0100$ ) (Fig. 3a-d). The same result was observed for NeuN (+) neuron immunoreactive area in the CA1 (one-way ANOVA $F_{(2,18)}=6.215$, $P=0.0089$ ) (Fig. 3e-h). The analysis of DCX (+) immature neurons revealed that the STZ injection decreased neurogenesis rate dramatically, which was not reversed by the stem cell therapy (one-way ANOVA $F_{(2,18)}=82.42$, $P<0.0001$ ) (Fig. 3i-1).

\section{MSC Therapy Ameliorated Microgliosis but Not Astrogliosis of the Hippocampus}

In order to evaluate the immunomodulatory effect of MSC in the brain, we studied the microglial and astroglial cells. We confirmed that STZ injection produced an overwhelming inflammatory gliosis. GFAP immunoreactive area assessment showed a vast increase in the STZ group; this astrogliosis could not be reversed by the MSC therapy (one-way ANOVA $F_{(2,18)}=30.53, P<0.0001$ ) (Fig. $4 \mathrm{a}-$ d). In order to figure out whether the cause of this increment of immunoreactive area was hyperplasia or hypertrophy, we estimated GFAP $(+)$ cell number. We did not find

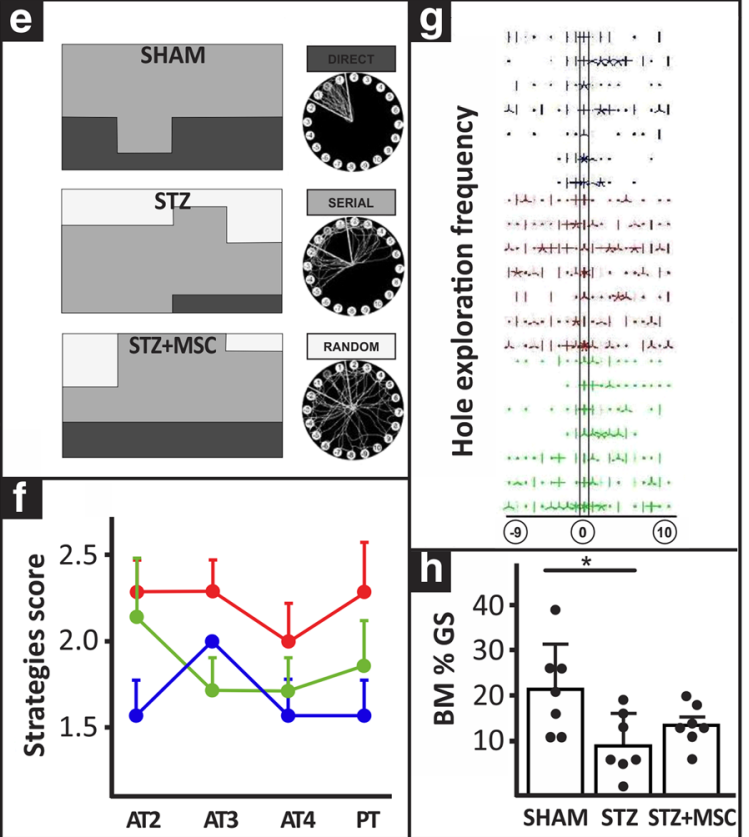

promoted some STZ subjects to shift towards a serial strategy instead. The sunflower plot (g) depicted the hole exploration frequency in the PT. The STZ treatment produced a decrease in the percentage of GS exploration frequency (h) in the PT, while the STZ + MSC group displayed a higher number of this parameter as compared with STZ group, but this difference was not significant. Abbreviation: $A T$, acquisition trial; $B M$, Barnes maze; $G S$, goal sector; $P T$, probe trial. All data were represented as mean \pm SEM. $N=7$ per group. $* P<0.05$. The undepicted comparisons account for a non-significant difference between groups

any significant difference in the GFAP(+) astrocytes number in the experimental groups (Supplementary Fig. S1A. One-way ANOVA $\left.F_{(2,18)}=1.772, P=0.1983\right)$, suggesting that the mechanism of astrogliosis was hypertrophy, rather than hyperplasia.

In addition, we recorded no differences in SR branching complexity, neither in the mean length of astrocyte processes, nor in the number of branches emerging from the cell soma in the Sholl analysis (Supplementary Fig. S1B-D. Two-way ANOVA group factor $F_{(2,18)}=1.176, P=0.3311$; one-way ANOVA $F_{(2,18)}=1.365, P=0.2807$; one-way ANOVA $F_{(2,18)}=0.9792, P=0.3947$, respectively). This result indicates that entire arbors were conserved 3 months after STZicv administration.

By means of Ibal immunohistochemistry, we recorded an important rise in the total number of Ibal cells in STZ and STZ + MSC groups (Supplementary Fig. S2. One-way ANOVA $\left.F_{(2,18)}=10.86, P=0,0008\right)$. As we evaluated cell morphology, STZ displayed a significant increase in the percentage of reactive microglia (activated stage) together with a decrease of non-reactive microglia (resting stage); these STZ-induced modifications were ameliorated by MSC therapy (two-way ANOVA group factor $\left.F_{(2,36)}=59.39, P<0.0001\right)$ (Fig. $4 \mathrm{e}-\mathrm{h}$ ). 


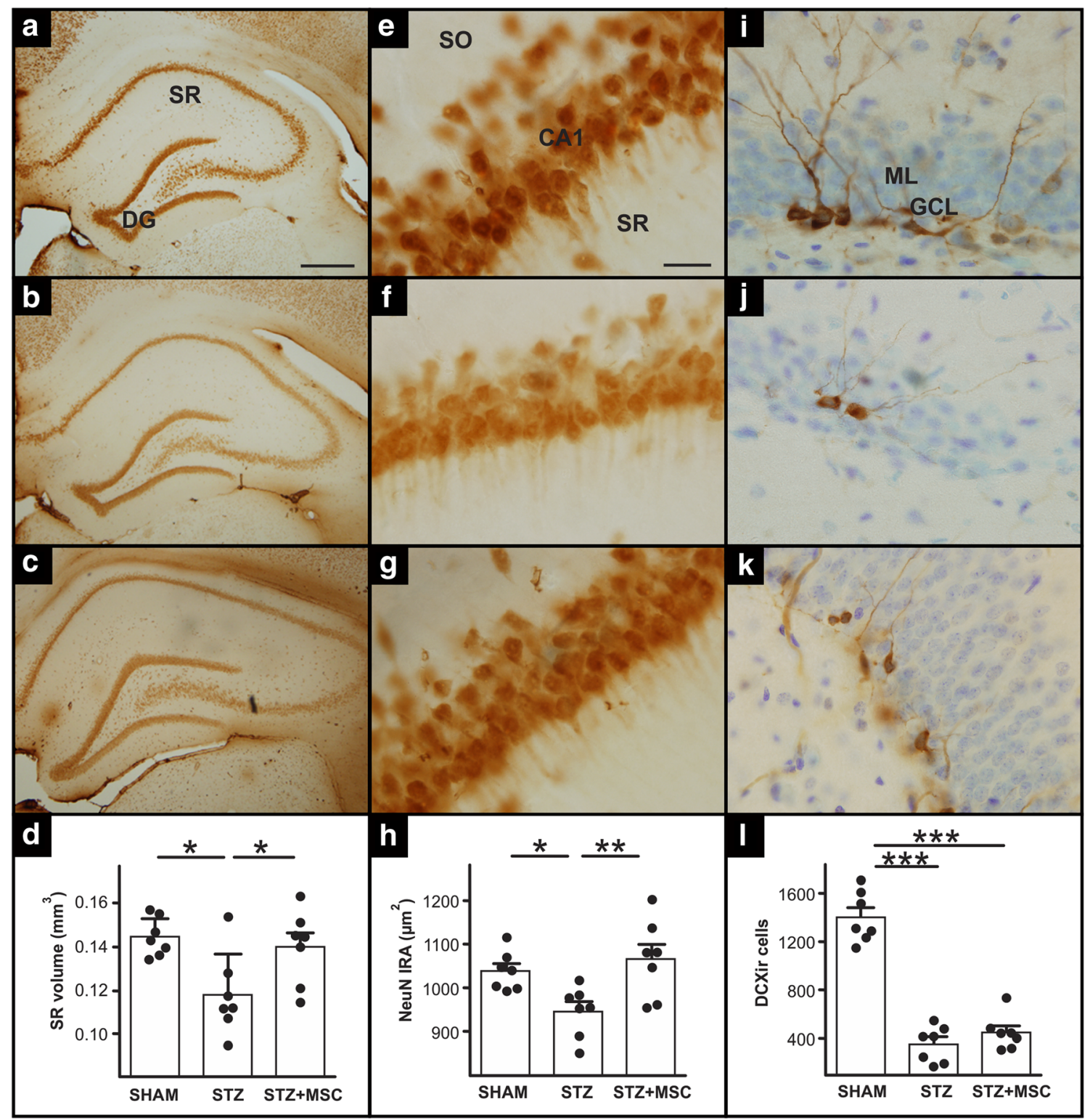

Fig. 3 Morphometric analysis of Stratum Radiatum (SR) volume, mature neuron in CA1 pyramidal cells, and immature neurons in dentate gyrus. Coronal sections of the $\mathrm{SR}$ in representative animals of each group showing NeuN immunoreactive (NeuNir) cells (a-c, 40×; e-g, 1000×). Quantification of the SR volume (d) showing a hippocampal atrophy process in the STZ-treated group and an improvement with the MSC treatment. A reduction in NeuN IRA in the hippocampal CA1 pyramidal layer (h) was observed in STZ group and it was reversed by MSC therapy. DCX expression in the DG of in representative animals of each group

\section{Synaptic Protein Levels After MSC Therapy}

Since synaptic dysfunction of the hippocampus is characteristic of $\mathrm{AD}$, we set out to evaluate whether MSC therapy restored the levels of relevant synaptic proteins in the SAD model. STZ rats displayed a significant reduction in SYT1 (Fig. 5d), SYP (Fig. 5e), and GAD 65 (Fig. 5i) protein levels, which was reversed by the MSC therapy (one-way ANOVA showing DCXir neurons (i-k). DCX cell numbers are plotted in l. Note the sharp STZ-related fall in DCX cell numbers. Abbreviations: CA1, Cornus Ammoni 1; DCXir, doublecortin immunoreactive; $D G$, dentate gyrus; $G C L$, granular cell layer; IRA, immunoreactive area; $M L$, molecular layer; SO, Stratum Oriens; SR, Stratum Radiatum. Scale bar $250 \mu \mathrm{m}$ (a) and $25 \mu \mathrm{m}$ (e). $N=7$ per group. All data were represented as mean \pm SEM. Comparisons were made between groups. $* P<0.05$; $* * P<0.01$; $* * * P<0.001$. The undepicted comparisons account for a non-significant difference between groups

$F_{(2,18)}=6.696, P=0.0067 ; F_{(2,18)}=7.792, P=0.0036$; $F_{(2,18)}=6.019, P=0.0100$, respectively). SYT2 protein level was decreased in STZ rats, while STZ + MSC group did not differ from the SHAM control (one-way ANOVA $F_{(2,18)}=$ $5.350, P=0.0150)$. Of note, we did not find any significant difference in SV2 and GAD67 protein levels (one-way ANOVA $F_{(2,18)}=3.101, P=0.0696 ; F_{(2,18)}=2.962, P=$ 0.0772). 
Fig. 4 MSC therapy effect on GFAP immunoreactive astrocytes and Ibal immunoreactive microglial cells in the hippocampal Stratum Radiatum. Coronal sections of the SR in representative animals of each group SHAM (a, e), STZ (b, f), and STZ + MSC (c, g), showing GFAPir (a, b, c, 40×; right magnified microphotography: $1000 \times)$ and Iba1 ir (e, f, g, 40×; right magnified

microphotography: 600×) cells. Quantification of GFAP IRA (d) displayed a vast increase in the STZ group that could not be reversed by the MSC therapy. Analysis of \%Ibal reactive and non-reactive cells (h); notice a dramatic increase in Iba1 reactive cells in STZ group and a significant decrease caused by the MSC therapy. On the contrary, Iba1 non-reactive cells show a decrease in STZ group and higher levels in STZ + MSC group. Abbreviations: IRA, immunoreactive area; $S R$, Stratum Radiatum. Scale bar $50 \mu \mathrm{m}$ (a and e). $N=7$ per group. All data were represented as mean \pm SEM. Comparisons were made between groups. $* P<0.05 ; * * * P<0.001$; $* * * * P<0.0001$. The undepicted comparisons account for a nonsignificant difference between groups

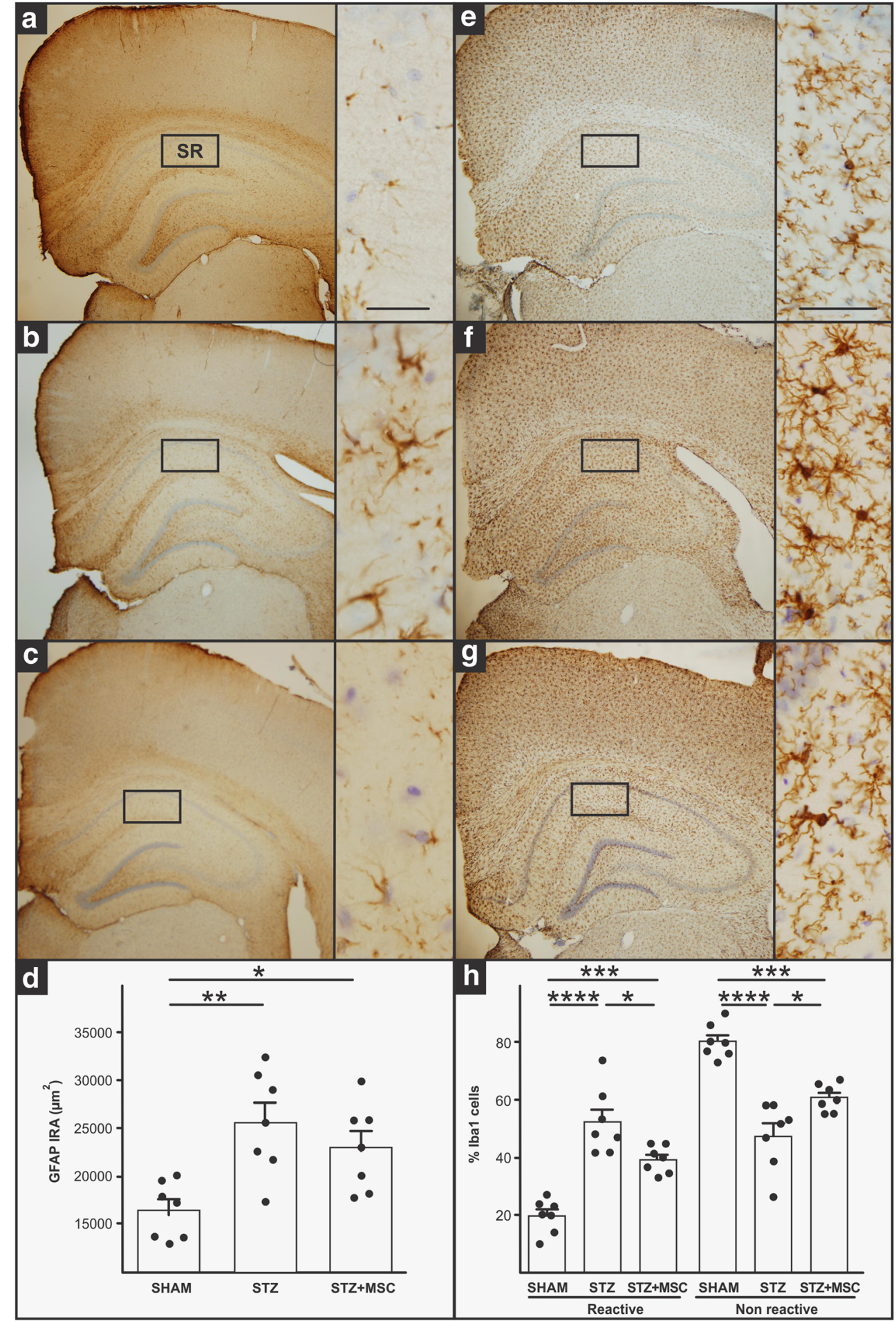

\section{Discussion}

In the current study, we used icv-STZ injection in rats, a model widely accepted due to its recapitulation of several AD pathological features and behavioral phenotypes, which was previously validated by us and others $[2,7-16]$.
To the best of our knowledge, MSC administration in the icv-STZ rat model of SAD has been hitherto poorly investigated $[48,49]$. Among the therapies, intracerebral engraftment strategies using MSC in animal models of neurodegenerative disorders, other than $\mathrm{AD}$, have been shown to improve cognitive deficits $[28,30,32,50]$. In fact, we have previously 

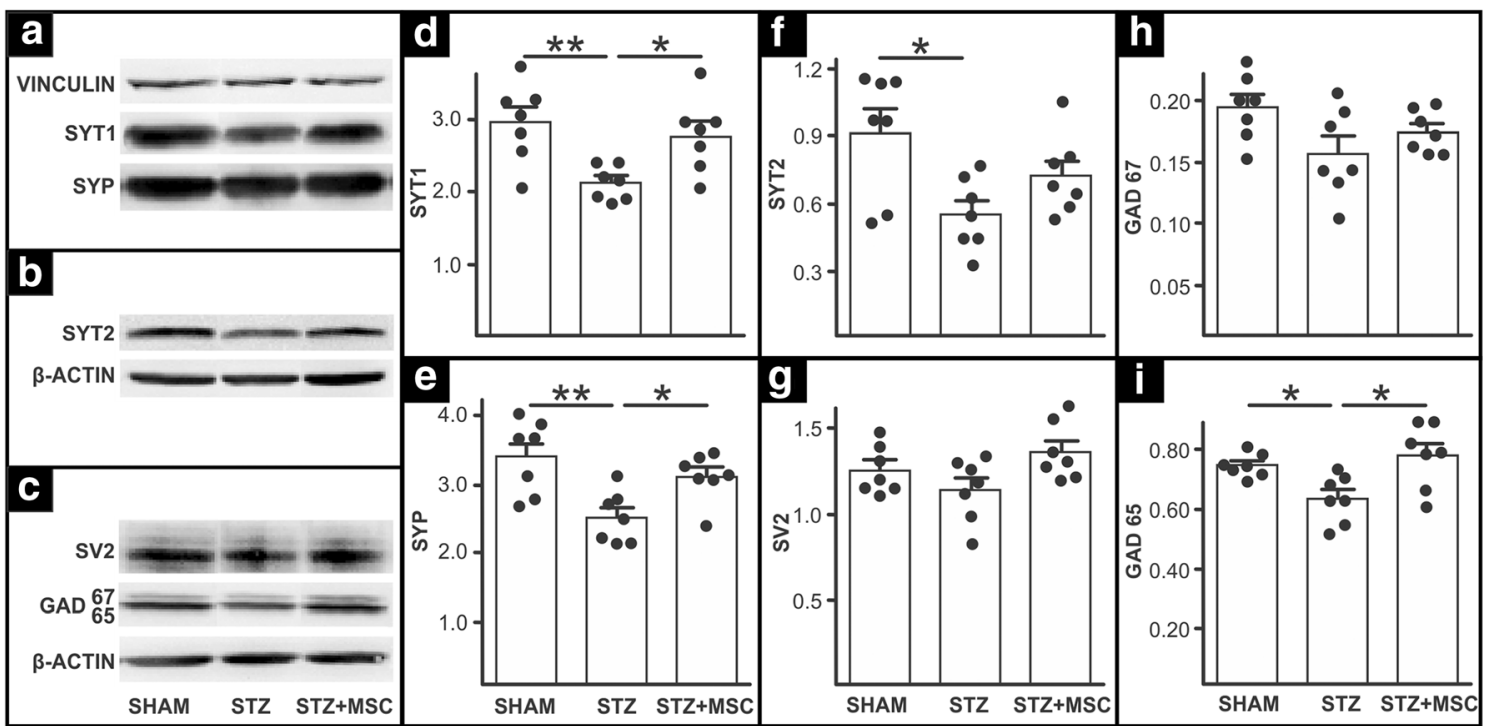

Fig. 5 MSC therapy effect on rat synaptic protein levels. Representative images of Vinculin, SYT1 and SYP (a), SYT2 and $\beta$-actin (b), and SV2, GAD 67, GAD 65, and $\beta$-Actin (c) rat hippocampal protein levels of each experimental group. Quantification of protein levels of SYT1 (d), SYP (e), SYT2 (f), SV2 (g), GAD67 (h), and GAD 65 (i), normalized to relative density of Vinculin $(\mathbf{d}-\mathbf{e})$ or $\beta$-actin $(\mathbf{f}-\mathbf{i})$, as previously shown in $\mathbf{a}, \mathbf{b}$, and $\mathbf{c}$. A significant decrease in SYT1, SYT2, SYP, and GAD65

shown that icv-MSC therapy exerts neuroprotective effects [51] and cognitive improvement $[51,52]$ in the aging rat. In the present study, however, we chose a less-invasive route for delivery of MSC (intravenous), which allowed us to perform a long-term treatment employing repeated (4 in 10 weeks) MSC injections in the $\mathrm{AD}$ model. Importantly, in order to minimize the risk of emboli formation, we resuspended the cells in a large volume of saline and injected them very slowly and carefully at a rate of $10 \mu \mathrm{l} / \mathrm{s}$ [53].

Recent works have shown the safety of this injection paradigm [53], with clear clinical advantages over direct central nervous system (CNS) administration [54]. Thus, in a study in cynomolgus monkeys, no stem cell transplantation toxicity was found after umbilical cord MSC injection once every 2 weeks, for 6 weeks [55]. Most importantly, in a phase I clinical trial, a research group evaluated the safety of intrathecal and intravenous transplantation of autologous bone marrow cells in children with cerebral palsy. They were evaluated for motor and cognitive functions, and finally by MRI, which showed this procedure was safe [56].

Furthermore, other studies have indicated that iv-MSC can migrate and localize into brain regions in different models of ischemic stroke [57, 58], Huntington's disease [59], and AD [60]. Moreover, some initial research suggested that MSC engrafted at the site of injury could differentiate into neuronal cells [61-63]. However, the importance of engraftment and frequency of transdifferentiation remains controversial. In fact, it is also known that iv administered MSC accumulate in the lungs and have a short systemic survival time [64]. For protein levels were observed for the STZ group, whereas cell therapy led to a recovery of SYT1, SYP, and GAD65 levels. Abbreviation: SYT, synaptotagmin; $S Y P$, synaptophysin; $S V 2$, synaptic vesicle protein 2; $G A D$, glutamic acid decarboxylase. $N=7$ per group. All data are represented as mean \pm SEM. Comparisons were made between groups. $* P<0.05 ; * * P<0.01$. The undepicted comparisons account for a nonsignificant difference between groups

that reason, only a small percentage of implanted MSC could reach the inflamed tissue, suggesting that their therapeutic action might be due to the bioactive molecules with immunomodulatory and trophic activities that they secrete $[65,66]$. More recently, it has been also demonstrated that monocytes and neutrophils contribute to the clearance of MSC from the lungs by phagocytosis and, subsequently, these cells migrate via the blood stream to other body sites. In turn, phagocytosis of MSC induced functional changes in monocytes, which then modulated the adaptive immune cell compartment [67]. In line with this, previous studies have indicated that MSC lead to neuroprotection via interaction with non-neurological organ systems such as the spleen in traumatic brain injury [68]. Taking all these into account, we suggest that the MSC therapeutic effect could be mediated by soluble factors or other cells such as microglial cells or monocyte/macrophages.

During the OF test, the natural tendency of animals in a new environment is its exploration. In line with previous findings that demonstrated the exploratory and anxiety behavior decline in this model $[69,70]$, rats receiving STZ presented higher grooming time and less crossing activity, indicative of their poor exploratory behavior. We also observed an increase in their anxiety behavior, as represented by the lower entries to the inner area. MSC rats improved these parameters as they were similar to those of the control group, corroborating the beneficial effect exerted by MSC therapy against exploratory and anxiety behavior impairment. It is worth noting that, before the initiation of cognitive assessment, we evaluated motor performance and no significant differences were found in icv- 
STZ animals (data not shown), in accordance with our previous studies and others [15, 71-73].

Deterioration in the ability to perform "activities of daily living" is an early sign of AD. It has been proposed that the species-typical behavior in laboratory rodents could be considered equivalent to these human activities [74, 75]. Rats bury familiar and unfamiliar objects (marbles) placed into their home cages as a species-typical behavior [41, 75]. Recently, it was observed that the integrity of the hippocampus is vital for the performance of species-typical tasks of mice [74]. In this work, icv-STZ leads to decreased burying in the MB test. In line with this observation, previously reported results showed that transgenic AD mice (Tg-APP/PS1) buried fewer marbles than non-transgenic mice [76]. Importantly, MSC therapy significantly ameliorated the marble burying behavior in STZ rats. Therefore, we suggest the treatment improves hippocampal function, which is consequently reflected in this species-typical behavior recovery.

We observed that, 3 months after icv-STZ, BM spatial learning of the rats was fairly preserved; contrarily, STZ rats showed an affected spatial memory, as evidenced by a rise in errors and an increasing trend of latency in the PT. These results are in accordance with our previous study performed within a month after icv-STZ [15] and also replicated the spatial memory deficits observed in the Morris water maze $[77,78]$. The present results demonstrated that MSC treatment was able to improve the aforementioned STZ-induced memory deficits observed in the PT. Moreover, we found that MSC therapy showed a tendency to restore goal seeking activity in the strategies carried out along the ATs and PT (i.e., less use of random search strategy) and improved memory retention during the PT, two components that contribute to the magnitude of the goal hole exploration frequency.

Several studies proposed that volume and neuronal loss in CA1 of the hippocampal formation are early hallmarks of AD and are strongly correlated with cognitive status $[3,4,15,79$, 80]. In a recent report, STZ induced neurodegeneration in the hippocampus, particularly in the CA1 area, 21 days after icv injection [81]. In our previous work, we similarly observed a decrease in NeuN immunostaining in STZ rats, which we suggested to be related to neuronal death in the dorsal hippocampus [15]. In accordance, in the present work, our results show that 3-month icv-STZ induces a SR volume reduction and CA1 pyramidal neurons loss. Interestingly, we observed that MSC therapy restored both SR volume and neuron loss. It is likely that the paracrine signaling of MSC could ameliorate structural SR and CA1 atrophy of STZ-induced hippocampal neurodegeneration and cognitive impairment.

The DG niche of adult born neurons is susceptible to deteriorate under several factors, e.g., aging and $\mathrm{AD}$ [44, 82]. In this regard, the STZ injection produced an overt decrease in the neurogenesis rate, which had been previously observed $[83,84]$. Since MSC therapy improved cognitive function of several and varied orders, our results give rise to two theses: either DG adult neurogenesis is dispensable to carry out the cognitive tasks hereby evaluated, or, if not, therapy is able to circumvent or compensate for this hippocampal feature by reactive microglia regulation and the protection of mature neurons and synapses. Further studies are needed to investigate these possibilities in detail.

It is well-established that neuroinflammation plays a significant role in $\mathrm{AD}$ [85-88]. In the CNS, astrocytes and microglial cells are often activated in neurodegenerative diseases. As mentioned above, the icv-STZ caused a frank increase in hippocampal gliosis, which is in line with previous studies at different time points post injection [15, 89-91] and it seems to contribute to cognitive deficits in the STZ-induced sAD model [83].

In a previous report, 25 days after STZ-icv, we observed an increased GFAPir area without change in GFAPir cell number [15], a similar effect observed in the present study, 95 days post injection. This suggests that, in this STZ model, hippocampal astrocytes are hypertrophied. In this line, AD patients were found to display GFAP hyper-reactivity with signs of cellular hypertrophy in the hippocampus [92] and in the cerebral cortex [93]. Based on our current work, MSC therapy did not exert a pronounced effect on the astrocytic population.

One relevant feature of AD and the senile brain is the progressive development of reactive microglia [94, 95]. Previously, we evaluated the effect of MSC on the senile rat brain, where we found that MSC therapy did not change the total number of microglial cells but reduced the proportion of reactive cells instead [51]. In accordance with this previous work, iv-MSC therapy decreased the reactive microglial cells, although it actually failed to reach the SHAM levels. Thus, we suggest that the neuroprotective effect of MSC could be mediated by the conversion of microglial cells to a different phenotype. It is known that microglial activation is heterogeneous and has been categorized into two opposite types: proinflammatory M1 phenotype (classical activation) and antiinflammatory M2 phenotype (alternative activation) [96].

In line with this hypothesis, MSC have been shown to reprogram M1-to-M2 switching in microglia and to improve neuron survival $[30,97,98]$. Additionally, it has been reported that MSC are able to maintain the resting phenotype or to control microglial activation through their production of several factors [99]. MSC have also been shown to inhibit activated microglia proliferation in vitro by modulating the cytokine response [100].

Consequently, MSC impact on microglia, either by secreting paracrine molecules or by direct cell-to-cell contacts, can cover different aspects given the multiple MSC's capacities. Thus, the aforementioned anti-inflammatory/immunomodulatory [17-19, 97, 100-102] and regenerative [103, 104] properties could inhibit M1 microglia proliferation, whereas activated microglia could be converted to the M2 phenotype. 
Since the determination of cytokines, M1/M2 microglia population, and MSC integration were beyond our scope, further studies will be needed to elucidate the effect of MSC on microglia.

It has been established that synaptic loss, a widely characterized feature in $\mathrm{AD}$, is a major correlate of cognitive impairment [105], suggesting a causal role for dwindling synaptic integrity in the etiology of the disease [106-108]. In the present study, we observed decreased levels of presynaptic proteins in the hippocampus of STZ animals. Interestingly, MSC treatment restored the levels of SYT1, SYP, and GAD65 synaptic markers, indicating that the cell therapy confers protection against synaptic proteins loss. Although the specific mechanism remains to be further studied, the synaptic proteins reduced in STZ group are known to affect the neuron transmitter release, thereby affecting the physiological functions of the neurons [108-112]. As we discussed before, the hippocampal volume is highly involved in behavioral functions. Consequently, cell therapy presumably restores the physiological functions of the hippocampal neurons by protecting the synaptic integrity.

It was previously shown that microglial processes make intimate but transient connections with neuronal synaptic elements $[113,114]$. In our work, we observed a long-lasting hippocampal microglial activation in the STZ rats, which has been shown, to be related to pro-inflammatory cytokines release by other studies. This in turn contributes to cognitive function impairment [115-118]. MSC treatment prevented cognitive damage in the STZ rats, as demonstrated in the behavioral tests, whose mechanism we speculate to be related to reduced inflammation and synaptic protection.

A diabetes rodent model widely used consists of intraperitoneal (ip) injection of STZ. This induces a vast increase in blood glucose levels and similar effects as our icv-STZ model in the brain and cognition. Two recent studies on this model have revealed interesting findings, mostly in line with our current work. Thus, in one work, bone marrow-derived mesenchymal stem cells were iv injected in STZ ip injected mice [119]. This cell therapy led to a shorter latency in finding the target quadrant in the Morris water maze, as well as to a higher time spent in the target quadrant. In the hippocampal CA1, they found the therapy increased NeuN cell count, SYP levels, and decreased Iba1 total cells, thus counteracting STZ effects. Interestingly, they observed the same effects in the hippocampus by replacing the cell therapy with an icv injection of the purified exosomal fraction of the stem cells, suggesting that the therapeutic effect was mediated by secreted factors inside the exosomes. The same group published 2 years later a study which showed that an enriched environment (EE) alleviated cognitive deficit and restored CA1 NeuN immunoreactivity and SYP levels in the ip-STZ model. The authors suggested a mechanism for this effect would be an anti-inflammatory action of endogenous bone marrow MSC-derived exosomes, which, under EE, produce great amounts of miR-146a [120]. Even though this is a different model of cognitive deficit, it provides strong evidence that MSC exosomes carry relevant neuroprotective molecules, which is of great interest towards novel therapies against $\mathrm{AD}$.

Overall, the present data show that the iv-MSC injection is a promising therapy to restore behavioral decline, a characteristic symptom of sAD. Our study supports the concept that the neuroprotection of the injected MSC is exerted by their restorative capacity on structural hippocampal atrophy, neurodegeneration and, partially, microgliosis. STZ-activated microglia release a variety of pro-inflammatory and cytotoxic factors whose accumulation is thought to contribute to the loss of neurons. However, a relevant finding is that hippocampal gliosis may play a significant role in burying behavior recovery together with an improvement of synaptic damage.

The development of MSC therapy for neurodegenerative diseases is still in its early stages and future studies should be pursued to unravel specific mechanisms of this promising treatment. In this regard, based on recent and growing evidence, MSC exosome therapy would provide a fair trade-off between treatment efficacy and animal cell engraftmentrelated risks.

\section{Conclusion}

In summary, the results obtained from our study reveal the effectiveness of repeated intravenous administration of human umbilical cord MSC to treat behavioral impairment and neurodegeneration caused by icv-STZ in rats, at 3-month postinjury. Our data demonstrate a MSC potential in the treatment of neurodegenerative diseases such as $\mathrm{SAD}$ by regulating microglial activation and rescuing hippocampal volume reduction, mature neuron loss, and synaptic proteins levels.

Acknowledgments The authors thank to Dr. Rodolfo G. Goya, Dr. Claudia B. Hereñú, Ms. Natalia S. Scelsio, and Ms. Romina Becerra for technical assistance, Ms. Rosana del Cid for English edition, Mr. Mario R. Ramos for graphic design, and Mr. Oscar Vercellini, Ms. Araceli Bigres, and Mr. Juan Manuel Lofeudo for animal care assistance. GRM, MGG, GM, and PCR are career researchers of the Argentine Research Council (CONICET). JLH is a recipient of CONICET doctoral fellowship. MFZV and JP are recipients of CONICET post-doctoral fellowships.

Funding Information This work was supported by grant \#PICT15-1998 from the Argentine Agency for Science and Technology (ANPCyT) and grant \#PIP0570 from CONICET to PCR.

\section{Compliance with Ethical Standards}

Conflict of Interest The authors declare that there are no conflicts of interest. 
Statement on the Welfare of Animals All applicable international, national, and/or institutional (INIBIOLP's Animal Welfare Assurance \#A5647-01) guidelines for the care and use of animals were followed. All procedures performed in studies involving animals were in accordance with the ethical standards of the institution or practice at which the studies were conducted. IACUC, Protocol \#P03-03-2016.

\section{References}

1 Alzheimer's Association (2016) 2016 Alzheimer's disease facts and figures. Alzheimers Dement 12:459-509

2 Gupta S, Yadav K, Mantri SS, Singhal NK, Ganesh S, Sandhir R (2018) Evidence for compromised insulin signaling and neuronal vulnerability in experimental model of sporadic Alzheimer's disease. Mol Neurobiol 55:8916-8935

3 Su L, Hayes L, Soteriades S, Williams G, Brain SAE, Firbank MJ, Longoni G, Arnold RJ et al (2018) Hippocampal Stratum Radiatum, Lacunosum, and Moleculare sparing in mild cognitive impairment. J Alzheimers Dis 61:415-424

4 Bobinski M, de Leon MJ, Tarnawski M, Wegiel J, Reisberg B, Miller DC, Wisniewski HM (1998) Neuronal and volume loss in CA1 of the hippocampal formation uniquely predicts duration and severity of Alzheimer disease. Brain Res 805:267-269

5 West MJ, Coleman PD, Flood DG, Troncoso JC (1994) Differences in the pattern of hippocampal neuronal loss in normal ageing and Alzheimer's disease. Lancet 344:769-772

6 Llorens-Martín M, Blazquez-Llorca L, Benavides-Piccione R, Rabano A, Hernandez F, Avila J, DeFelipe J (2014) Selective alterations of neurons and circuits related to early memory loss in Alzheimer's disease. Front Neuroanat 8:38

7 Grünblatt E, Salkovic-Petrisic M, Osmanovic J, Riederer P, Hoyer S (2007) Brain insulin system dysfunction in streptozotocin intracerebroventricularly treated rats generates hyperphosphorylated tau protein. J Neurochem 101:757-770

8 Salkovic-Petrisic M, Hoyer S (2007) Central insulin resistance as a trigger for sporadic Alzheimer-like pathology: an experimental approach. J Neural Transm Suppl:217-233

9 Shoham S, Bejar C, Kovalev E, Weinstock M (2003) Intracerebroventricular injection of streptozotocin causes neurotoxicity to myelin that contributes to spatial memory deficits in rats. Exp Neurol 184:1043-1052

10 Shonesy BC, Thiruchelvam K, Parameshwaran K, Rahman EA, Karuppagounder SS, Huggins KW, Pinkert CA, Amin R et al (2012) Central insulin resistance and synaptic dysfunction in intracerebroventricular-streptozotocin injected rodents. Neurobiol Aging 33:430.e5-430.18

11 Blokland A, Jolles J (1993) Spatial learning deficit and reduced hippocampal ChAT activity in rats after an ICV injection of streptozotocin. Pharmacol Biochem Behav 44:491-494

12 Blokland A, Jolles J (1994) Behavioral and biochemical effects of an ICV injection of streptozotocin in old Lewis rats. Pharmacol Biochem Behav 47:833-837

13 Prickaerts J, Blokland A, Honig W, Meng F, Jolles J (1995) Spatial discrimination learning and choline acetyltransferase activity in streptozotocin-treated rats: effects of chronic treatment with acetyl-L-carnitine. Brain Res 674:142-146

14 Veerendra Kumar MH, Gupta YK (2003) Effect of Centella asiatica on cognition and oxidative stress in an intracerebroventricular streptozotocin model of Alzheimer's disease in rats. Clin Exp Pharmacol Physiol 30:336-342

15 Zappa Villar MF, López Hanotte J, Falomir Lockhart E, Trípodi LS, Morel GR, Reggiani PC (2018) Intracerebroventricular streptozotocin induces impaired Barnes maze spatial memory and reduces astrocyte branching in the CA1 and CA3 hippocampal regions. J Neural Transm (Vienna) 125:1787-1803

16 Rostami F, Javan M, Moghimi A, Haddad-Mashadrizeh A, Fereidoni M (2017) Streptozotocin-induced hippocampal astrogliosis and insulin signaling malfunction as experimental scales for subclinical sporadic Alzheimer model. Life Sci 188: $172-185$

17 Foraker JE, Oh JY, Ylostalo JH, Lee RH, Watanabe J, Prockop DJ (2011) Cross-talk between human mesenchymal stem/progenitor cells (MSCs) and rat hippocampal slices in LPS-stimulated cocultures: the MSCs are activated to secrete prostaglandin E2. J Neurochem 119:1052-1063

18 Kwon MS, Noh MY, Oh KW, Cho KA, Kang BY, Kim KS, Kim YS, Kim SH (2014) The immunomodulatory effects of human mesenchymal stem cells on peripheral blood mononuclear cells in ALS patients. J Neurochem 131:206-218

19 Sheikh AM, Nagai A, Wakabayashi K, Narantuya D, Kobayashi S, Yamaguchi S, Kim SU (2011) Mesenchymal stem cell transplantation modulates neuroinflammation in focal cerebral ischemia: contribution of fractalkine and IL-5. Neurobiol Dis 41:717-724

20 Aquino JB, Bolontrade MF, García MG, Podhajcer OL, Mazzolini G (2010) Mesenchymal stem cells as therapeutic tools and gene carriers in liver fibrosis and hepatocellular carcinoma. Gene Ther 17:692-708

21 Donega V, Nijboer CH, van Tilborg G, Dijkhuizen RM, Kavelaars A, Heijnen CJ (2014) Intranasally administered mesenchymal stem cells promote a regenerative niche for repair of neonatal ischemic brain injury. Exp Neurol 261:53-64

22 Prockop DJ, Oh JY (2012) Medical therapies with adult stem/ progenitor cells (MSCs): a backward journey from dramatic results in vivo to the cellular and molecular explanations. J Cell Biochem 113:1460-1469

23 Baksh D, Yao R, Tuan RS (2007) Comparison of proliferative and multilineage differentiation potential of human mesenchymal stem cells derived from umbilical cord and bone marrow. Stem Cells 25: 1384-1392

24 Bayo J, Fiore E, Aquino JB, Malvicini M, Rizzo M, Peixoto E, Alaniz L, Piccioni F et al (2014) Human umbilical cord perivascular cells exhibited enhanced migration capacity towards hepatocellular carcinoma in comparison with bone marrow mesenchymal stromal cells: a role for autocrine motility factor receptor. Biomed Res Int 2014:837420

25 Huang PY, Shih YH, Tseng YJ, Ko TL, Fu YS, Lin YY (2016) Xenograft of human umbilical mesenchymal stem cells from Wharton's jelly as a potential therapy for rat pilocarpine-induced epilepsy. Brain Behav Immun 54:45-58

26 Li J, Yawno T, Sutherland AE, Gurung S, Paton M, McDonald C, Tiwari A, Pham Y et al (2018) Preterm umbilical cord blood derived mesenchymal stem/stromal cells protect preterm white matter brain development against hypoxia-ischemia. Exp Neurol 308: $120-131$

27 Sarugaser R, Lickorish D, Baksh D, Hosseini MM, Davies JE (2005) Human umbilical cord perivascular (HUCPV) cells: a source of mesenchymal progenitors. Stem Cells 23:220-229

28 Bantubungi K, Blum D, Cuvelier L, Wislet-Gendebien S, Rogister B, Brouillet E, Schiffmann SN (2008) Stem cell factor and mesenchymal and neural stem cell transplantation in a rat model of Huntington's disease. Mol Cell Neurosci 37:454-470

29 Kim KS, Kim HS, Park JM, Kim HW, Park MK, Lee HS, Lim DS, Lee TH et al (2013) Long-term immunomodulatory effect of amniotic stem cells in an Alzheimer's disease model. Neurobiol Aging 34:2408-2420

30 Lee HJ, Lee JK, Lee H, Carter JE, Chang JW, Oh W, Yang YS, Suh JG et al (2012) Human umbilical cord blood-derived mesenchymal stem cells improve neuropathology and cognitive impairment in an 
Alzheimer's disease mouse model through modulation of neuroinflammation. Neurobiol Aging 33:588-602

31 Song CG, Zhang YZ, Wu HN, Cao XL, Guo CJ, Li YQ, Zheng MH, Han H (2018) Stem cells: a promising candidate to treat neurological disorders. Neural Regen Res 13:1294-1304

32 Zappa Villar MF, Lehmann M, Garcia MG, Mazzolini G, Morel GR, Console GM, Podhajcer O, Reggiani PC et al (2019) Mesenchymal stem cell therapy improves spatial memory and hippocampal structure in aging rats. Behav Brain Res In Press. https:// doi.org/10.1016/j.bbr.2019.04.001

33 Dominici M, Le Blanc K, Mueller I, Slaper-Cortenbach I, Marini F, Krause D, Deans R, Keating A et al (2006) Minimal criteria for defining multipotent mesenchymal stromal cells. The International Society for Cellular Therapy position statement. Cytotherapy 8 : 315-317

34 Paxinos G, Watson C (1998) The rat brain in stereotaxic coordinates. Academic Press, San Diego

35 Walsh RN, Cummins RA (1976) The open-field test: a critical review. Psychol Bull 83:482-504

36 Dong MX, Li CM, Shen P, Hu QC, Wei YD, Ren YF, Yu J, Gui SW et al (2018) Recombinant tissue plasminogen activator induces long-term anxiety-like behaviors via the ERK1/2-GAD1-GABA cascade in the hippocampus of a rat model. Neuropharmacology 128:119-131

37 Tatem KS, Quinn JL, Phadke A, Yu Q, Gordish-Dressman H, Nagaraju K (2014) Behavioral and locomotor measurements using an open field activity monitoring system for skeletal muscle diseases. J Vis Exp 51785

38 Kalueff AV, Tuohimaa P (2005) The grooming analysis algorithm discriminates between different levels of anxiety in rats: potential utility for neurobehavioural stress research. J Neurosci Methods 143:169-177

39 Morel GR, Andersen T, Pardo J, Zuccolilli GO, Cambiaggi VL, Hereñu CB, Goya RG (2015) Cognitive impairment and morphological changes in the dorsal hippocampus of very old female rats. Neuroscience 303:189-199

40 Locklear MN, Bhamidipaty S, Kritzer MF (2015) Local N-methyld-aspartate receptor antagonism in the prefrontal cortex attenuates spatial cognitive deficits induced by gonadectomy in adult male rats. Neuroscience 288:73-85

41 Poling A, Cleary J, Monaghan M (1981) Burying by rats in response to aversive and nonaversive stimuli. J Exp Anal Behav 35: 31-44

42 Bahi A (2016) Sustained lentiviral-mediated overexpression of microRNA124a in the dentate gyrus exacerbates anxiety- and autism-like behaviors associated with neonatal isolation in rats. Behav Brain Res 311:298-308

43 Glowinski J, Iversen LL (1966) Regional studies of catecholamines in the rat brain. I. The disposition of $[3 \mathrm{H}]$ norepinephrine, $[3 \mathrm{H}]$ dopamine and $[3 \mathrm{H}]$ dopa in various regions of the brain. $\mathrm{J}$ Neurochem 13:655-669

44 Pardo J, Uriarte M, Cónsole GM, Reggiani PC, Outeiro TF, Morel GR, Goya RG (2016) Insulin-like growth factor-I gene therapy increases hippocampal neurogenesis, astrocyte branching and improves spatial memory in female aging rats. Eur J Neurosci 44: 2120-2128

45 West MJ (1993) New stereological methods for counting neurons. Neurobiol Aging 14:275-285

46 Diz-Chaves Y, Astiz M, Bellini MJ, Garcia-Segura LM (2013) Prenatal stress increases the expression of proinflammatory cytokines and exacerbates the inflammatory response to LPS in the hippocampal formation of adult male mice. Brain Behav Immun 28:196-206

47 Sholl DA (1953) Dendritic organization in the neurons of the visual and motor cortices of the cat. J Anat 87:387-406
48 Isik AT, Celik T, Ural AU, Tosun M, Ulusoy G, Elibol B (2016) Mesenchymal stem cell therapy for the streptozotocin-induced neurodegeneration in rats. Neurol Res 38:364-372

49 Mohammadi A, Maleki-Jamshid A, Milan PB, Ebrahimzadeh K, Faghihi F, Joghataei MT (2018) Intrahippocampal transplantation of undifferentiated human chorionic-derived mesenchymal stem cells does not improve learning and memory in the rat model of sporadic Alzheimer disease. Curr Stem Cell Res Ther 14(2):184 190

50 Cho YH, Kim HS, Lee KH, Lee YE, Chang JW (2006) The behavioral effect of human mesenchymal stem cell transplantation in cold brain injured rats. Acta Neurochir Suppl 99:125-132

51 Zappa Villar MF, Lehmann M, García MG, Mazzolini G, Morel GR, Cónsole GM, Podhajcer O, Reggiani PC et al (2019) Mesenchymal stem cell therapy improves spatial memory and hippocampal structure in aging rats. Behav Brain Res 2:111887

52 Lehmann M, Zappa-Villar MF, García MG, Mazzolini G, Canatelli-Mallat M, Morel GR, Reggiani PC, Goya RG (2019) Umbilical cord cell therapy improves spatial memory in aging rats. Stem Cell Rev 15:612-617. https://doi.org/10.1007/s12015-01909895-2

53 Ra JC, Shin IS, Kim SH, Kang SK, Kang BC, Lee HY, Kim YJ, Jo JY et al (2011) Safety of intravenous infusion of human adipose tissue-derived mesenchymal stem cells in animals and humans. Stem Cells Dev 20(8):1297-1308

54 Jackson JS, Golding JP, Chapon C, Jones WA, Bhakoo KK (2010) Homing of stem cells to sites of inflammatory brain injury after intracerebral and intravenous administration: a longitudinal imaging study. Stem Cell Res Ther 1(2):17

55 Wang Y, Han ZB, Ma J, Zuo C, Geng J, Gong W, Sun Y, Li H et al (2012) A toxicity study of multiple-administration human umbilical cord mesenchymal stem cells in cynomolgus monkeys. Stem Cells Dev 3:1401-1408

56 Sharma A, Sane H, Gokulchandran N, Kulkarni P, Gandhi S, Sundaram J, Paranjape A, Shetty A et al (2015) A clinical study of autologous bone marrow mononuclear cells for cerebral palsy patients: a new frontier. Stem Cells Int 2015:905874

57 Yilmaz G, Vital S, Yilmaz CE, Stokes KY, Alexander JS, Granger DN (2011) Selectin-mediated recruitment of bone marrow stromal cells in the postischemic cerebral microvasculature. Stroke 42(3): 806-811

58 Wei L, Fraser JL, Lu ZY, Hu X, Yu SP (2012) Transplantation of hypoxia preconditioned bone marrow mesenchymal stem cells enhances angiogenesis and neurogenesis after cerebral ischemia in rats. Neurobiol Dis 46(3):635-645

59 Edalatmanesh MA, Matin MM, Neshati Z, Bahrami AR, Kheirabadi M (2010) Systemictransplantation of mesenchymal stem cells can reduce cognitive and motor deficits in rats with unilateral lesions of the neostriatum. Neurol Res 32(2):166-172

60 Panchenko MM, Poltavtseva RA, Bobkova NV, Vel'meshev DV, Nesterova IV, Samokhin AN, Sukhikh GT (2014) Localization and differentiation pattern of transplanted human multipotent mesenchymal stromal cells in the brain of bulbectomized mice. Bull Exp Biol Med 158:118-122

61 Bae KS, Park JB, Kim HS, Kim DS, Park DJ, Kang SJ (2011) Neuron-like differentiation of bone marrow-derived mesenchymal stem cells. Yonsei Med J 52:401-412

62 Kopen GC, Prockop DJ, Phinney DG (1999) Marrow stromal cells migrate throughout forebrain and cerebellum, and they differentiate into astrocytes after injection into neonatal mouse brains. Proc Natl Acad Sci U S A 96(19):10711-10716

63 Qu C, Mahmood A, Lu D, Goussev A, Xiong Y, Chopp M (2008) Treatment of traumatic brain injury in mice with marrow stromal cells. Brain Res 1208:234-239

64 Eggenhofer E, Luk F, Dahlke MH, Hoogduijn MJ (2014) The life and fate of mesenchymal stem cells. Front Immunol 5:148 
65 English K (2013) Mechanisms of mesenchymal stromal cell immunomodulation. Immunol Cell Biol 91(1):19-26

66 Uccelli A, de Rosbo NK (2015) The immunomodulatory function of mesenchymal stem cells: mode of action and pathways. Ann N Y Acad Sci 1351:114-126

67 de Witte SFH, Luk F, Sierra Parraga JM, Gargesha M, Merino A, Korevaar SS, Shankar AS, O'Flynn L et al (2018) Immunomodulation by therapeutic mesenchymal stromal cells (MSC) is triggered through phagocytosis of MSC by monocytic cells. Stem Cells 36(4):602-615

68 Walker PA, Shah SK, Jimenez F, Gerber MH, Xue H, Cutrone R, Hamilton JA, Mays RW et al (2010) Intravenous multipotent adult progenitor cell therapy for traumatic brain injury: preserving the blood brain barrier via an interaction with splenocytes. Exp Neurol 225(2):341-352

69 Fedotova J, Soultanov V, Nikitina T, Roschin V, Ordyan N, Hritcu L (2016) Ropren ${ }^{\circledR}$ treatment reverses anxiety-like behavior and monoamines levels in gonadectomized rat model of Alzheimer's disease. Biomed Pharmacother 83:1444-1455

70 Hosseinzadeh S, Zahmatkesh M, Heidari M, Hassanzadeh GR, Karimian M, Sarrafnejad A, Zarrindast MR (2015) Hippocampal DHCR24 down regulation in a rat model of streptozotocin-induced cognitive decline. Neurosci Lett 587:107-112

71 Bokare AM, Bhonde M, Goel R, Nayak Y (2018) 5-HT6 receptor agonist and antagonist modulates ICV-STZ-induced memory impairment in rats. Psychopharmacology 235:1557-1570

72 Ozkay UD, Can OD, Ozkay Y, Oztürk Y (2012) Effect of benzothiazole/piperazine derivatives on intracerebroventricular streptozotocin-induced cognitive deficits. Pharmacol Rep 64: 834-847

73 Saxena G, Patro IK, Nath C (2011) ICV STZ induced impairment in memory and neuronal mitochondrial function: a protective role of nicotinic receptor. Behav Brain Res 224:50-57

74 Deacon RMJ, Rawlins JNP (2005) Hippocampal lesions, speciestypical behaviours and anxiety in mice. Behav Brain Res 156:241249

75 Deacon RM (2006) Digging and marble burying in mice: simple methods for in vivo identification of biological impacts. Nat Protoc $1: 122-124$

76 Kim TK, Han HE, Kim H, Lee JE, Choi D, Park WJ, Han PL (2012) Expression of the plant viral protease NIa in the brain of a mouse model of Alzheimer's disease mitigates $A \beta$ pathology and improves cognitive function. Exp Mol Med 44:740-748

77 Guo Z, Chen Y, Mao YF, Zheng T, Jiang Y, Yan Y, Yin X, Zhang B (2017) Long-term treatment with intranasal insulin ameliorates cognitive impairment, tau hyperphosphorylation, and microglial activation in a streptozotocin-induced Alzheimer's rat model. Sci Rep 7:45971

78 Salkovic-Petrisic M, Knezovic A, Osmanovic-Barilar J, Smailovic U, Trkulja V, Riederer P, Amit T, Mandel S et al (2015) Multitarget iron-chelators improve memory loss in a rat model of sporadic Alzheimer's disease. Life Sci 136:108-119

79 Elgh E, Lindqvist Astot A, Fagerlund M, Eriksson S, Olsson T, Näsman B (2006) Cognitive dysfunction, hippocampal atrophy and glucocorticoid feedback in Alzheimer's disease. Biol Psychiatry 59:155-161

80 Stoub TR, deToledo-Morrell L, Stebbins GT, Leurgans S, Bennett DA, Shah RC (2006) Hippocampal disconnection contributes to memory dysfunction in individuals at risk for Alzheimer's disease. Proc Natl Acad Sci U S A 103:10041-10045

81 Majkutewicz I, Kurowska E, Podlacha M, Myślińska D, Grembecka B, Ruciński J, Plucińska K, Jerzemowska G et al (2016) Dimethyl fumarate attenuates intracerebroventricular streptozotocin-induced spatial memory impairment and hippocampal neurodegeneration in rats. Behav Brain Res 308:24-37
82 Lazarov O, Marr RA (2010) Neurogenesis and Alzheimer's disease: at the crossroads. Exp Neurol 223:267-281

83 Bassani TB, Bonato JM, Machado MMF, Cóppola-Segovia V, Moura ELR, Zanata SM, Oliveira RMMW, Vital MABF (2018) Decrease in adult neurogenesis and neuroinflammation are involved in spatial memory impairment in the streptozotocininduced model of sporadic Alzheimer's disease in rats. Mol Neurobiol 55:4280-4296

84 Sun P, Knezovic A, Parlak M, Cuber J, Karabeg MM, Deckert J, Riederer P, Hua Q et al (2015) Long-term effects of Intracerebroventricular streptozotocin treatment on adult neurogenesis in the rat hippocampus. Curr Alzheimer Res 12: 772-784

85 Bronzuoli MR, Iacomino A, Steardo L, Scuderi C (2016) Targeting neuroinflammation in Alzheimer's disease. J Inflamm Res 9:199 208

86 Cameron B, Landreth GE (2010) Inflammation, microglia, and Alzheimer's disease. Neurobiol Dis 37:503-509

87- Medeiros R, LaFerla FM (2013) Astrocytes: conductors of the Alzheimer disease neuroinflammatory symphony. Exp Neurol 239:133-138

88 Spangenberg EE, Green KN (2017) Inflammation in Alzheimer's disease: lessons learned from microglia-depletion models. Brain Behav Immun 61:1-11

89 Kraska A, Santin MD, Dorieux O, Joseph-Mathurin N, Bourrin E, Petit F, Jan C, Chaigneau M et al (2012) In vivo cross-sectional characterization of cerebral alterations induced by intracerebroventricular administration of streptozotocin. PLoS One 7(9):e46196

90 Rodrigues L, Dutra MF, Ilha J, Biasibetti R, Quincozes-Santos A, Leite MC, Marcuzzo S, Achaval M et al (2010) Treadmill training restores spatial cognitive deficits and neurochemical alterations in the hippocampus of rats submitted to an intracerebroventricular administration of streptozotocin. J Neural Transm (Vienna) 117: 1295-1305

91 Weinstock M, Shoham S (2004) Rat models of dementia based on reductions in regional glucose metabolism, cerebral blood flow and cytochrome oxidase activity. J Neural Transm (Vienna) 111:347366

92 Biasibetti R, Tramontina AC, Costa AP, Dutra MF, QuincozesSantos A, Nardin P, Bernardi CL, Wartchow KM et al (2013) Green tea (-)epigallocatechin-3-gallate reverses oxidative stress and reduces acetylcholinesterase activity in a streptozotocininduced model of dementia. Behav Brain Res 1 236(1):186-193

93 Vijayan VK, Geddes JW, Anderson KJ, Chang-Chui H, Ellis WG, Cotman CW (1991) Astrocyte hypertrophy in the Alzheimer's disease hippocampal formation. Exp Neurol 112(1):72-78

94 Luo XG, Ding JQ, Chen SD (2010) Microglia in the aging brain: relevance to neurodegeneration. Mol Neurodegener 24(5):12

95 Norden DM, Godbout JP (2013) Review: microglia of the aged brain: primed to be activated and resistant to regulation. Neuropathol Appl Neurobiol 39(1):19-34

96 Tang Y, Le W (2016) Differential roles of M1 and M2 microglia in neurodegenerative diseases. Mol Neurobiol 53(2):1181-1194

97 Bian P, Ye C, Zheng X, Yang J, Ye W, Wang Y, Zhou Y, Ma H et al (2017) Mesenchymal stem cells alleviate Japanese encephalitis virus-induced neuroinflammation and mortality. Stem Cell Res Ther 8(1):38

98 Ohtaki H, Ylostalo JH, Foraker JE, Robinson AP, Reger RL, Shioda S, Prockop DJ. Stem/progenitor cells from bone marrow decrease neuronal death in global ischemia by modulation of inflammatory/immune responses (2008) Proc Natl Acad Sci USA 105(38):14638-14643.

99 Yan K, Zhang R, Sun C, Chen L, Li P, Liu Y, Peng L, Sun H et al (2013) Bone marrow-derived mesenchymal stem cells maintain the resting phenotype of microglia and inhibit microglial activation. PLoS One 8(12):e84116 
100 Jose S, Tan SW, Ooi YY, Ramasamy R, Vidyadaran S (2014) Mesenchymal stem cells exert anti-proliferative effect on lipopolysaccharide-stimulated BV2 microglia by reducing tumour necrosis factor- $\alpha$ levels. J Neuroinflammation 3(11): 149

101 Le Blanc K, Mougiakakos D (2012) Multipotent mesenchymal stromal cells and the innate immune system. Nat Rev Immunol 12:383-396

102 Vercelli A, Mereuta OM, Garbossa D, Muraca G, Mareschi K, Rustichelli D, Ferrero I, Mazzini L et al (2008) Human mesenchymal stem cell transplantation extends survival, improves motor performance and decreases neuroinflammation in mouse model of amyotrophic lateral sclerosis. Neurobiol Dis 31:395-405

103 Drommelschmidt K, Serdar M, Bendix I, Herz J, Bertling F, Prager S, Keller M, Ludwig AK et al (2017) Mesenchymal stem cellderived extracellular vesicles ameliorate inflammation-induced preterm brain injury. Brain Behav Immun 60:220-232

104 Lin W, Xu L, Zwingenberger S, Gibon E, Goodman SB, Li G (2017) Mesenchymal stem cells homing to improve bone healing. J Orthop Translat 9:19-27

105 Terry RD, Masliah E, Salmon DP, Butters N, DeTeresa R, Hill R, Hansen LA, Katzman R (1991) Physical basis of cognitive alterations in Alzheimer's disease: synapse loss is the major correlate of cognitive impairment. Ann Neurol 30:572-580

106 Forner S, Baglietto-Vargas D, Martini AC, Trujillo-Estrada L, LaFerla FM (2017) Synaptic impairment in Alzheimer's disease: a dysregulated symphony. Trends Neurosci 40:347-357

107 Kirvell SL, Esiri M, Francis PT (2006) Down-regulation of vesicular glutamate transporters precedes cell loss and pathology in Alzheimer's disease. J Neurochem 98:939-950

108 Sze CI, Troncoso JC, Kawas C, Mouton P, Price DL, Martin LJ (1997) Loss of the presynaptic vesicle protein synaptophysin in hippocampus correlates with cognitive decline in Alzheimer disease. J Neuropathol Exp Neurol 56:933-944

109 Schwab C, Yu S, Wong W, McGeer EG, McGeer PL (2013) GAD65, GAD67, and GABAT immunostaining in human brain and apparent GAD65 loss in Alzheimer's disease. J Alzheimers Dis 33:1073-1088

110 Südhof TC (2013) Neurotransmitter release: the last millisecond in the life of a synaptic vesicle. Neuron 80:675-690

111 Zhang R, Zhao M, Ji HJ, Yuan YH, Chen NH (2013) Study on the dynamic changes in synaptic vesicle-associated protein and axonal transport protein combined with LPS neuroinflammation model. ISRN Neurol 2013:496079

112 Rodrigues Hell RC, Silva Costa MM, Goes AM, Oliveira AL (2009) Local injection of BDNF producing mesenchymal stem cells increases neuronal survival and synaptic stability following ventral root avulsion. Neurobiol Dis 33:290-300

113 Ojo B, Rezaie P, Gabbott PL, Davies H, Colyer F, Cowley TR, Lynch M, Stewart MG (2012) Age-related changes in the hippocampus (loss of synaptophysin and glial-synaptic interaction) are modified by systemic treatment with an NCAM-derived peptide, FGL. Brain Behav Immun 26:778-788

114 Wake H, Moorhouse AJ, Jinno S, Kohsaka S, Nabekura J (2009) Resting microglia directly monitor the functional state of synapses in vivo and determine the fate of ischemic terminals. J Neurosci 29: 3974-3980

115 Jiang T, Yu JT, Tan L (2012) Novel disease-modifying therapies for Alzheimer's disease. J Alzheimers Dis 31:475-492

116 Perry VH, O'Connor V (2010) The role of microglia in synaptic stripping and synaptic degeneration: a revised perspective. ASN Neuro 2:e00047

117 Pourbadie HG, Sayyah M, Khoshkholgh-Sima B, Choopani S, Nategh M, Motamedi F, Shokrgozar MA (2018) Early minor stimulation of microglial TLR2 and TLR4 receptors attenuates Alzheimer's disease-related cognitive deficit in rats: behavioral, molecular, and electrophysiological evidence. Neurobiol Aging 70:203-216

118 Streit WJ, Sammons NW, Kuhns AJ, Sparks DL (2004) Dystrophic microglia in the aging human brain. Glia 45:208-212

119 Nakano M, Nagaishi K, Konari N, Saito Y, Chikenji T, Mizue Y, Fujimiya M (2016) Bone marrow-derived mesenchymal stem cells improve diabetes-induced cognitive impairment by exosome transfer into damaged neurons and astrocytes. Sci Rep 22(6):24805

120 Kubota K, Nakano M, Kobayashi E, Mizue Y, Chikenji T, Otani M, Nagaishi K, Fujimiya M (2018) An enriched environment prevents diabetes-induced cognitive impairment in rats by enhancing exosomal miR-146a secretion from endogenous bone marrowderived mesenchymal stem cells. PLoS One 13(9):e0204252

Publisher's Note Springer Nature remains neutral with regard to jurisdictional claims in published maps and institutional affiliations. 